\title{
Seasonal variation in non-specific bronchial reactivity: a study of wheat workers with a history of wheat associated asthma
}

\author{
MICHAEL J HENSLEY, RAPHAEL SCICCHITANO, NICHOLAS A SAUNDERS, \\ ALLAN W CRIPPS, JOHN RUHNO, DAVID SUTHERLAND, ROBERT L CLANCY
}

From the Departments of Community Medicine, Medicine, and Pathology, Faculty of Medicine, University of Newcastle, and the Hunter Immunology Unit, Royal Newcastle Hospital, Newcastle, New South Wales, Australia

ABSTRACT To investigate seasonal variation in non-specific bronchial reactivity in wheat workers, we carried out histamine inhalation tests in 29 workers (28 of them men) from a small farming community with symptoms of wheat associated asthma before, during and after the 1983-4 Australian wheat harvest season. Four were cigarette smokers, and the age range was 12-54 (mean (SD) 30 (10)) years. Twenty eight subjects were atopic (one positive skinprick test result in tests with 10 common antigens), $60 \%$ reacting to house dust mite and all to at least one of eight wheat antigens. Baseline spirometry gave normal results (mean $\mathrm{FVC}_{1}$ 90\% (SD 8\%) predicted; FVC 91\% (7\%) predicted). Bronchial reactivity was tested by the method of Yan et al. The cumulative doses of histamine acid phosphate (up to $3.91 \mu \mathrm{mol}$ ) that caused a fall of $20 \%$ from baseline in FEV 1 was determined $\left(\mathrm{PD}_{20}\right)$ and expressed as the geometric mean. In the low exposure season, May 1983, nine subjects had a $\mathrm{PD}_{20}$ (mean $1 \cdot 2$, range $0 \cdot 3-3.9 \mu \mathrm{mol}$ ). The number rose to 19 in the summer harvest season, December 1983 (mean 0.8, range 0.07-3.9 $\mu \mathrm{mol}$ ) and returned to nine in the subsequent winter, July 1984 (mean 1.8, range $0 \cdot 4-3 \cdot 9 \mu \mathrm{mol}$ ). The change in the number of subjects with a $\mathrm{PD}_{20}$ was significant $(\mathrm{p}<0.01)$. Four additional subjects probably had increased bronchial reactivity in the harvest season: in two the post-saline $\mathrm{FEV}_{1}$ was too unstable to give them histamine challenge and in two the challenge was inadvertently discontinued prematurely. Baseline $\mathrm{FEV}_{1}$ and FVC fell by $8 \%$ between the first and second studies $(p<0.001)$; values were intermediate in the third study $\left(\mathrm{FEV}_{1}\right.$ $3.74,3.44$, and 3.57; FVC 4.66, 4.28, and 4.41 litres respectively). Linear modelling analysis of $\log \mathrm{PD}_{20}$, season, $\mathrm{FEV}_{1}, \mathrm{FVC}$, age, seasonality of asthma symptoms and skin test data indicated that the harvest season was the only significant determinant of variation in $\log P_{20}$. It is concluded that in these wheat workers there is a seasonal variation in bronchial reactivity that may reflect a response to allergens associated with grain.

Asthma is acknowledged to be a considerable health problem in an increasing number of occupations. ${ }^{12}$ The harvesting, drying, and transportation of grain, its milling, and the handling of flour have all been associated with illness of both the upper and the lower respiratory tracts..$^{3-6}$

An increase in non-specific bronchial reactivity is

Address for reprint requests: Associate Professor M J Hensley, Centre for Clinical Epidemiology and Biostatistics, David Maddison Building Level 3, Royal Newcastle Hospital, Newcastle, New South Wales 2300, Australia.

Accepted 9 October 1987 generally accepted as present in most if not all patients with current or symptomatic asthma ${ }^{78}$ and it has been suggested that the measurement of non-specific bronchial reactivity should be an essential requirement for establishing the diagnosis of asthma, especially in epidemiological studies. ${ }^{9}$ Non-specific bronchial reactivity is not stable, however, and it has been shown to vary spontaneously, with respiratory infections, with allergen exposure, with treatment, and with the severity of asthma as reflected by drug requirements or symptoms. ${ }^{10-15}$

In this study 29 wheat workers with a history of asthma like symptoms on exposure to wheat were 
investigated for changes in non-specific bronchial reactivity before, during, and after the Australian wheat harvest season of 1983-4. Our major hypothesis was that seasonal exposure to wheat would be associated with a seasonal change in bronchial reactivity.

\section{Methods}

The study was carried out in the wheat district of New South Wales in a town of about 1900 people situated 450 kilometres north west of Newcastle. The 29 subjects were studied on each of three occasions: May 1983 (late autumn), December 1983 (summer), and July 1984 (winter).

In May 1983 we studied 66 local inhabitants who had either upper or lower respiratory tract symptoms on exposure to wheat. Of these, 57 had symptoms consistent with asthma according to the criteria of the American Thoracic Society. ${ }^{16}$ Of the subjects with asthma, 33 volunteered to be studied in December 1983 and 31 in July 1984 . We report the results on 29 subjects who participated on all three occasions. All subjects gave informed consent. The project was approved by the ethics committee of the University of Newcastle.

\section{SYMPTOMS AND QUESTIONNAIRE}

Asthma was classified according to whether it occurred only on exposure to grain or at other times throughout the year, such as with a respiratory tract infection. This latter group was designated "Perennial." The timing of symptoms of cough, wheeze, and dyspnoea in relation to exposure to grain was classified as "immediate" if they occurred on contact or "delayed" if symptoms came on later that day or evening. Each subject completed the ATSDLD 78 questionnaire during the first study, though none of these data have been used in this analysis. Since we could not validly document asthma symptoms during the entire harvest season (December 1983-January 1984), we did not try to use asthma like symptoms for any purpose other than to select subjects.

\section{SPIROMETRY}

Forced vital capacity (FVC) and forced expiratory volume in one second $\left(\mathrm{FEV}_{1}\right)$ were measured with a dry wedge spirometer (Vitalograph) calibrated with a three litre syringe. Volumes were not corrected to BTPS because of the evidence that expired air does not cool to ambient temperature with a Vitalograph and that full correction to BTPS gives incorrectly large values. ${ }^{17}$ The best FEV , and FVC of at least three manoeuvres were recorded as the baseline values on each occasion. Predicted values were calculated from the formulae of Knudson et al. ${ }^{18}$

\section{BRONCHIAL REACTIVITY}

Non-specific bronchial reactivity was measured by a histamine inhalation test with the method of Yan et al. ${ }^{8}$ Following a control inhalation of nebulised saline, histamine acid phosphate was administered by a cumulative dose technique from four DeVilbis nebulisers containing concentations of $3 \cdot 13,6 \cdot 25,25$, and $50 \mathrm{mg} / \mathrm{ml}$ histamine acid phosphate. The procedure was stopped when the FEV , had fallen by $20 \%$ or more from the baseline. All subjects whose $\mathrm{FEV}_{1}$ did not fall by $20 \%$ received a cumulative dose of $3.91 \mu \mathrm{mol}$ of histamine. Nebulised salbutamol was administered after the histamine inhalation test to all subjects whose $\mathrm{FEV}$, had fallen by $10 \%$ or more.

Bronchial reactivity was calculated from a plot of change in $\mathrm{FEV}_{1}$ from baseline against log-dose of histamine. The dose at which $F E V_{1}$ was $20 \%$ lower than baseline $\left(\mathrm{PD}_{20}\right)$ was interpolated from the graph and expressed as the geometric mean.

\section{SKINPRICK TESTS}

During the third visit skinprick tests were carried out with 10 common antigens (Dermatophagoides pteronyssinius, D farinae, Aspergillus sp, mould mix, perennial rye grass, Timothy, seven grass mix, plaintain, dog, cat-Hollister-Stier). Atopy was defined as the presence of at least one positive skin test response (weal diameter of $3 \mathrm{~mm}$ or more at 15 minutes) Skinprick tests were also carried out with eight wheat antigens including commercially available extracts of cultivated wheat and wheat smut (Hollister-Stier) as well as extracts prepared in our own laboratorywheat whole grain, wheat chaff, wheat straw dustwheat grain dust, wheat header dust, wheat silo dust-according to the method of Baldo and Wrigley. ${ }^{19}$

\section{STA TISTICAL ANALYSIS}

For comparison of grouped data for seasonal change in bronchial reactivity, a Pearson $\chi^{2}$ test was performed. Comparison of changes in spirometric values were carried out by analysis of variance and $\varrho$ paired $t$ test. To explore the determinants of the changes in $\mathbf{P D}_{20}$ a regression analysis was carried out with the linear modelling program known as GLIM. ${ }^{20}$ The factors entered into the analysis included the results on the three occasions for FEV, FVC, and $\log \mathrm{PD}_{20}$ as well as age, asthma classified as "perennial" or "grain only" and a positive skinprick test reaction to house dust mite. 


\section{Results}

\section{DEMOGRAPHIC DETAILS AND BASELINE} SPIROMETRY

Of the twenty-nine subjects, there were nineteen farmers, three farm equipment mechanics, two exfarmers, two students, one farm-hand, one ex-wheatgrader and one stock carrier. There was one woman and the ages ranged from 12 to 54 (mean 30) years. There were four cigarette smokers. Eighteen subjects had symptoms on exposure to grain but not with any other precipitant (classified as "grain only"). Thirteen subjects (seven with "grain only" and six with "perennial" asthma) had only immediate symptoms on exposure to grain.

Treatment for asthma symptoms within the month preceding each study was as follows. May 1983 (autumn): 22 no treatment; 4 bronchodilator; 3 bronchodilator plus sodium cromoglycate or cortico steroids. December 1983 (summer harvest): 13 no treatment; 11 bronchodilator; 5 bronchodilator plus sodium cromoglycate or steroids. July 1984 (winter): 12 no treatment; 15 bronchodilator; 2 bronchodilator plus sodium cromoglycate or steroids. No subjects took a bronchodilator within six hours of the histamine challenge. Further details are available on request.

Baseline spirometric values in the first study were within normal limits (greater than $80 \%$ of the predicted value for $\mathrm{FEV}_{1}$ and FVC) for 27 of the 29 subjects. A 25 year old man had an $\mathrm{FEV}_{1}$ of $77 \%$ predicted and a 44 year old woman had an $\mathrm{FEV}_{1}$ of $70 \%$ predicted. Neither smoked. For the 29 subjects the mean $\mathrm{FEV}_{1}$ as a percentage of the predicted value was $90.4 \%$ (SD $8.0 \%$ ) and the mean FVC $91.3 \%$ $(7 \cdot 2 \%)$.

At the second study, during the harvest season, there was a fall of $8 \%$ in mean $\mathrm{FEV}_{1}$ (from 3.74 (SD0.6) to $3.44(0.6)$ litres; $p<0.001)$, with a subsequent rise at the third study $(3.57(0.59)$ litres: $\mathrm{p}=0.04)$. Changes in FVC were similar to those seen with $\mathrm{FEV}_{1}$ (from $4.66(0.73)$ to $4.28(0.63)$ to 4.41 $(0.68)$ 1). The data for $\mathrm{FEV}_{1}$ and FVC on the third occasion were from 28 subjects because one subject was unable to produce a repeatable forced expirogram.

\section{SKINPRICK TESTS}

Twenty eight of the twenty nine subjects had at least one positive skin test reaction to common antigens, the number of positive values ranging from 1 to 9 (mean 5 (SD 2-5)). Fifty nine per cent of subjects had a positive reaction to house dust mite. Comparison of the skin test results of the "grain only" and the "perennial" groups showed no substantial differences (for instance, "grain only" $61 \%$ positive for house dust mite, total positive results 4 (SD 2); "perennial" $55 \%$ positive for house dust mite; total positive results 5 (3)). All subjects had at least one positive reaction to one of eight wheat antigens. The prevalence of positive results ranged from $48 \%$ for wheat smut to $86 \%$ for wheat straw dust.

\section{HISTAMINE INHALATION TEST}

There was a change in bronchial reactivity between the harvest and non-harvest seasons when the results were analysed for the number of subjects with a $\mathbf{P D}_{20}$ $\left(\chi^{2}=6.91, \mathrm{p}<0.01\right.$; see table). Nine subjects had a $\mathrm{PD}_{20}$ on the first occasion (geometric mean $1 \cdot 2$, range $0.3-3.9 \mu \mathrm{mol}$ ), 19 on the second (mean 0.8 , range $0.07-$ $3.9 \mu \mathrm{mol}$ ), and nine on the third (mean 1.8 , range 0.4 $3.9 \mu \mathrm{mol})$.

On the second occasion (during the harvest season) there were two subjects whose post-saline FEV, was too unstable for the histamine inhalation test and two whose test was inadvertently stopped before a $20 \%$ fall in $\mathrm{FEV}_{1}\left(\mathrm{FEV}_{1}\right.$, had fallen by $10 \%$ or more after only 0.06 and $0.62 \mu \mathrm{mol}$ of histamine). On the third occasion (winter 1984) one subject's baseline spirometric values were too unstable for the histamine inhalation test.

The figure shows results for $\mathrm{PD}_{20}$ for 21 subjects. Omitted are five whose results were negative on all occasions and the three subjects with missing data described above. Two of the three subjects in the figure whose results were negative in the harvest season may have had a measurable $\mathrm{PD}_{20}$ if the histamine inhalation test had not been stopped prematurely.

\section{ANALYSIS OF DETERMINANTS OF BRONCHIAL REACTIVITY}

When a linear model of the data was constructed for age, type of asthma, presence or absence of atopy, and the results of $\mathrm{PD}_{20}, \mathrm{FEV}_{1}$, and $\mathrm{FVC}$ for the different seasons, the only significant explanatory variable for the variation in $\log \mathrm{PD}_{20}$ was season-that is, the second occasion, during the harvest season, was a significant determinant $(t=3.86, \mathrm{p}<0.001)$.

Spirometric and bronchial reactivity data

\begin{tabular}{|c|c|c|c|}
\hline & May 1983 & Dec 1983 & July 1984 \\
\hline $\begin{array}{l}\text { FEV }_{1}(1, \text { mean } \\
(\mathrm{SD}))\end{array}$ & $3.74(0.61)$ & $3.44(0.61)$ & $3.57\left(0.59^{*}\right)$ \\
\hline $\begin{array}{l}\text { FVC (l, mean (SD)) } \\
\text { No with positive } \\
\text { HIT }\end{array}$ & $\begin{array}{l}4.66(0 \cdot 73) \\
9\end{array}$ & ${ }_{19}^{4 \cdot 28(0 \cdot 62)}$ & $\begin{array}{l}4.41\left(0.68^{*}\right) \\
9\end{array}$ \\
\hline $\begin{array}{l}\mathrm{PD}_{20}(\mu \mathrm{mol}, \\
\text { geometric mean } \\
\text { (range)) }\end{array}$ & $1 \cdot 2(0.3-3 \cdot 9)$ & $0.8(0.07-3.9)$ & $1.8(0.4-3.9)$ \\
\hline
\end{tabular}

*28 subjects only.

$\mathrm{FEV}_{1}$, forced expiratory volume in one second; FVC, forced vital capacity; positive HIT, positive result in histamine inhalation test$\mathrm{PD}_{20}<3.9 \mu \mathrm{mol}$ histamine; $\mathrm{PD}_{20}$, dose of histamine causing a fall in FEV , of $20 \%$. 


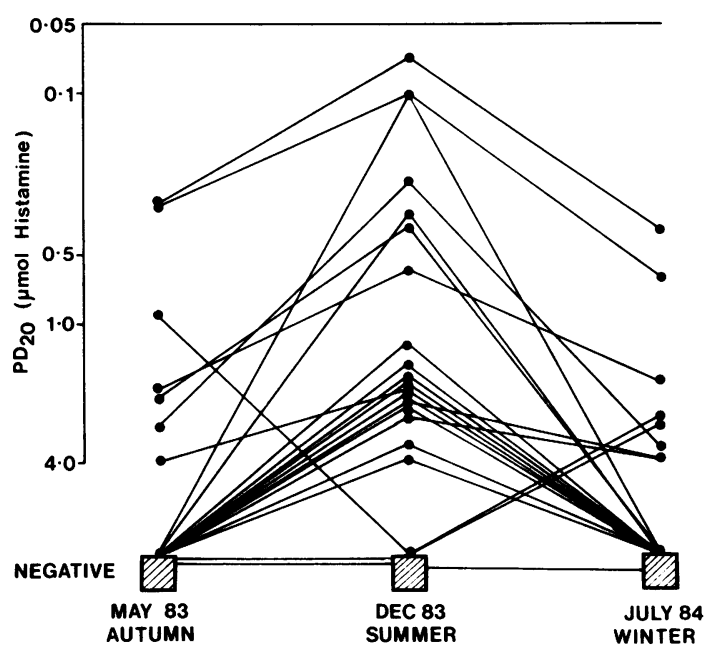

Change in bronchial reactivity by season in 21 of the 29 subjects, as assessed by the provocative dose of histamine causing a $20 \%$ fall in $F E V_{1}\left(P D_{20}\right)$, expressed in umol on a log scale. Five subjects who had a negative result on all occasions, and three subjects whose $P D_{20}$ could not be determined because of excessive variability in their spirometric values, are omitted.

\section{Discussion}

We have shown that bronchial reactivity, as measured by the presence of a $P_{20}$, in a group of 29 wheat workers increased during the summer harvest season and decreased in the subsequent winter to levels found in the autumn of the previous year. Before discussing our interpretation of these findings, we must consider certain methodological issues that may have influenced the results. These include the representativeness of the sample of subjects, the validity of the method for measuring bronchial reactivity, and the possible effect of reduction in lung function during the harvest season.

Since our subjects were all volunteers who had symptoms suggestive of asthma in the two years preceding our first test, they may not be representative of farmers in either the community or the state. These results cannot therefore be generalised to the wheat farming community. Furthermore, in the absence of measurements in a symptomless group we cannot validly assume any causal relationship between the increase in bronchial reactivity and the asthma like symptoms reported for the previous seasons. Despite these limitations, the results support the hypothesis that bronchial reactivity in wheat workers does change with the seasons coincidentally with changes in their symptoms. We did not ask about respiratory symptoms during the 1983-4 harvest season since the bronchial reactivity study was carried out early in the season and subjects who had symptoms later in the season would have been misclassified.

The technique for measurement of bronchial reactivity used in the present study has been extensively evaluated by $Y$ an and colleagues ${ }^{8}$ and more recently by Britton et al. ${ }^{21}$ We have carried out our own quality control studies, which showed reproducibility to be within one doubling dose of histamine in a group of volunteers from the medical school. We agree with the conclusion of Britton et $a^{20}$ that the Yan technique is a good test for use in epidemiological studies of bronchial reactivity.

An important consideration in the interpretation of our data is whether the $8 \%$ fall in $\mathrm{FEV}_{1}$ found in the second test could have affected the measurement of bronchial reactivity, via a change in airway geometry. To our knowledge there is no way to resolve this question in quantitative terms, but such a relatively small fall in FEV, seems unlikely to be associated with a substantial enough change in geometry to cause the variation in bronchial reactivity that we have measured. In support of this argument are the results from the third occasion, when there was a reversal of the increase in bronchial reactivity without complete return of lung function to previous values, the FEV, being on average $4.5 \%$ below that of the first occasion. Furthermore, the linear model analysis showed a highly significant effect of the season but not FEV , on the variation of $\mathrm{PD}_{20}$.

We conclude that the change in bronchial reactivity that we observed is real and not explained by any artefact. What is the possible mechanism of the change? There is a reasonable amount of evidence to support the hypothesis that an allergen induced inflammatory process may be responsible. Such a mechanism has been proposed by Boulet $e t a l^{13}$ and by Sotomayor $e$ al $^{22}$ for the seasonal changes they found in bronchial reactivity in patients with allergy to grass pollens. The case for the role of inflammation was strengthened by the finding in the latter study that the changes in bronchial reactivity were reversed by methylprednisolone $16 \mathrm{mg} /$ day but not by placebo. Since all but one of our subjects reacted to common antigens and all to wheat antigens, we believe that a similar mechanism may be operating in our subjects.

While the major aim of our study was to describe the seasonal variation in bronchial reactivity in wheat workers, our results can be used to assess the predic- $\theta$ tive value of bronchial reactivity tests done before exposure to an environment which is suspected to provoke asthma. Although all subjects had a history of asthma like symptoms in the previous two seasons, only nine out of 29 subjects had a measureable $\mathrm{PD}_{20}$ in the autumn before the harvest season. Over half of the "negative" subjects subsequently developed a measureable $\mathrm{PD}_{20}$ in the harvest season. These results, 
admittedly from a small sample, indicate that bronchial reactivity is not a biologically stable entity and bring into question its use except for research. There is still uncertainty about the appropriate role of bronchial reactivity in occupational medicine; the evidence is well summarised in a recent review. ${ }^{2}$

We thank the following people who contributed to the success of this project: D Best, C Clancy, D Lloyd, S Chin, J Wlodarczyk, C Wrigley (Commonwealth Scientific and Industrial Research Organisation), and the volunteers from the farming community. This work was supported by the Asthma Foundation of New South Wales, and the National Health and the Medical Research Council of Australia.

\section{References}

1 Davies RJ, Blainey AD. Occupational Asthma. In: Clark TJH, Godfrey S, eds. Asthma. Chapman and Hall, Cambridge: University Press, 1983:202-41.

2 Chan-Yeung M, Lam S. State of the art. Occupational asthma. Am Rev Respir Dis 1986;133:686-703.

3 Davies RJ, Green M, Schofield NMcC. Recurrent nocturnal asthma after exposure to grain dust. Am Rev Respir Dis 1976;114:1011-9.

4 Darke CS, Knowelden J, Lacey J, Milford Ward A. Respiratory disease of workers harvesting grain. Thorax 1976;31:294-302.

5 Warren CPW, Manfreda J. Respiratory symptoms in Manitoba farmers: association with grain and hay handling. Can Med Assoc J 1980;122:1259-64.

6 Dosman JA, Cotton DJ, eds. Occupational pulmonary disease: focus on grain dust and health. New York: Academic Press, 1980.

7 Cockcroft DW, Killian DN, Mellon JJA, Hargreaves FE. Bronchial reactivity to inhaled histamine: a method and clinical survey. Clin Allergy 1977;7:235-43.

8 Yan K, Salome C, Woolcock AJ. Rapid method for measurement of bronchial responsiveness. Thorax 1983;38:760-5.

9 Gregg I. Epidemiological aspects. In: Clark TJH, Godfrey S, eds. Asthma. Cambridge: Chapman and Hall, University Press, 1983:242-84.
10 Empey DW, Laitinen LA, Jacobs L, Gold WM, Nadel JA. Mechanism of bronchial hyper-reactivity in normal subjects after upper respiratory infection. $\mathrm{Am}$ Rev Respir Dis 1976;113:131.

11 Cockcroft DW, Ruffin RE, Dolovich J, Hargreave FE. Allergen-induced increase in non-allergic bronchial reactivity. Clin Allergy 1977;7:503-13.

12 Altounyan REC. Changes in histamine and atropine responsiveness as a guide to diagnosis and evaluation of therapy in obstructive airways disease. In: Pepys J, Frankland AW, eds. Disodium cromoglycate in allergic airways disease. London: Butterworth, 1969:47-53.

13 Boulet L-P, Cartier A, Thomson NC, Roberts RS, Dolovich J, Hargreave FE. Asthma and increases in nonallergic bronchial responsiveness from seasonal pollen exposure. J Allergy Clin Immunol 1983;71: 399-406.

14 Mink JT, Gerrard JW, Cockcroft DW, Cotton DJ, Dosman JA. Increased bronchial reactivity to inhaled histamine in non-smoking grain workers with normal lung function. Chest 1980;77:28-31.

15 Makino S. Clinical significance of bronchial sensitivity to acetylcholine and histamine in bronchial asthma. $J$ Allergy 1966;38:127-42.

16 American Thoracic Society. Definitions and classifications of chronic bronchitis, asthma and pulmonary emphysema. Am Rev Respir Dis 1962;85:762-8.

17 Perks NH, Sopwith T, Brown D, Jones CH, Green M. Effects of temperature on Vitalograph readings. Thorax 1983;38:592-4.

18 Knudson RJ, Slatin RC, Lebowitz MD, Burrows B. The maximum expiratory flow-volume curve: normal standards, variability and effects of age. Am Rev Respir Dis 1976;113:587-600.

19 Baldo BA, Wrigley CW. IgE antibodies to wheat flour compounds. Clin Allergy 1978;8:109-24.

20 Baker RJ, Nelder JA. The GLIM system generalised linear interactive modelling manual. Oxford: Numerical Algorithm Group, 1978.

21 Britton J, Mortagy A, Tattersfield A. Histamine callenge testing: comparison of three methods. Thorax 1986; 41:128-32.

22 Sotomayor H, Badier M, Vervloet D, Orehek J. Seasonal increase of carbachol airway responsiveness in patients allergic to grass pollen. Am Rev Respir Dis 1984; 130:56-8. 